\title{
High-resolution wave model validation over the Greek maritime areas
}

\author{
N. Mazarakis ${ }^{1}$, V. Kotroni ${ }^{1}$, K. Lagouvardos ${ }^{1}$, and L. Bertotti ${ }^{2}$ \\ ${ }^{1}$ National Observatory of Athens, Institute of Environmental Research and Sustainable Development, \\ I. Metaxa \& Vas. Pavlou, Lofos Koufou, 15236, P. Penteli, Athens, Greece \\ ${ }^{2}$ ISMAR, Institute of Marine Sciences, Arsenale - Tesa 104, Castello 2737/F, 30122 Venice, Italy
}

Correspondence to: N. Mazarakis (nickmaz@noa.gr)

Received: 28 May 2012 - Revised: 20 September 2012 - Accepted: 26 September 2012 - Published: 21 November 2012

\begin{abstract}
The increasing maritime activity can be seriously affected by severe weather and sea conditions. To avoid serious damages to ships, marine structures and humans, a good weather and wave forecast is of primary importance. In general the meteorological and the wave models are used to produce forecasts at large scale like the global or the medium-size inner seas. For much smaller environments like the Greek maritime areas, characterized by complicated features like the orography and the presence of islands, the modelisation becomes a not simple task.

This study is devoted to the validation of the performance of the WAM wave model over the Ionian and Aegean Seas. The period of validation refers to the first 12 months of operational use of the model at the National Observatory of Athens. The wave model is applied at a resolution of $1 / 16 \mathrm{de}-$ grees and is driven by the $10 \mathrm{~m}$ wind, produced by the BOLAM meteorological model operationally run over the same area. Two different sources of data have been used for the verification of the model results. The first dataset is provided by a network of buoys deployed over the Greek maritime areas and the second consists of altimeter data, provided by the OSTM/Jason-2 satellite platform. Although the study area is characterized by complex topography and a large number of islands, the implementation of the WAM model provides very encouraging results. In general, with the exception of the two buoys located in the Ionian Sea, the WAM model tends to underestimate the wave energy in the region of the Aegean Sea. The comparison with the altimeter data shows that the model has a tendency to overestimate the height for waves lower than $2.5 \mathrm{~m}$ and to underestimate the waves higher than $3 \mathrm{~m}$.
\end{abstract}

\section{Introduction}

The Aegean and Ionian Sea, located in the eastern part of Mediterranean, are two maritime regions characterized by large naval activity, not only for marine trades but also for sailing, fishing and other marine activities, especially during the summer season. The complexity of the shoreline and the topography and the large number of islands play a significant role in modulating the wind and the wave fields, creating, in many cases, ideal conditions for very strong winds and very high waves. An example is the etesians, local northerly dry winds, which blow from May to September over the Aegean Sea. They may create dangerous conditions for small vessels as their speed can exceed $15-20 \mathrm{~m} \mathrm{~s}^{-1}$ for a period of 1 to 6 consecutive days. For this reason the knowledge of the wave conditions, either as a forecast or as observation, is critical for all the human maritime activities including transportation, fishing and sailing.

During the last decades the development of operational wave models provided reliable forecasts, while the expanded use of space-borne altimeter data brought forth measurements for the sea state, especially in the open sea. The quality of wave forecasts, however, is strongly dependent on the regional characteristics, like the bathymetry and the wind field. In general the accuracy of the wave forecasts is better in the open ocean than in enclosed areas such as the Mediterranean Sea. The lower performance of wave models in limited marine regions than over open oceans has been attributed to the fact that wind forecasts are also less accurate than over the open oceans (Cavaleri and Bertotti, 2003, 2004; Ponce de Leon and Guedes Soares, 2008). 
Focusing on the Greek area, the two main marine regions, the Ionian and the Aegean Sea, are characterized by the presence of a very large number of small and large islands. These strongly influence not only the wind field, producing channelling or divergence effects over the sea, but also the wave field (Ponce de Len and Soares, 2005, 2010). As a consequence it is difficult to compute the wind as well as the wave fields close to the coast. However, the land effect on the wind field is gradually reduced far from the coasts (Lagouvardos et al., 2003).

The Mediterranean Sea is an enclosed basin surrounded by several important mountain ranges that strongly influence both the wind and the wave fields. Strong wind may cause heavy wave conditions which may be the cause of maritime disasters as described by Bertotti and Cavaleri (2008). The wind can be very strong, especially in the westerly part of the basin. This fact has brought to investigate and study more deeply the meteo-oceanographic features that characterize the area. An important study investigated the forecast accuracy of wave models in the western Mediterranean, comparing the wind and wave forecasts from various models with buoy measurements and satellite data (Ardhuin et al., 2007). In a more recent study, a modified version of WAM4 and WW3 models was applied in hindcast mode to simulate the wave regime in the Mediterranean Sea for a 2-yr evaluation period (Korres et al., 2011). Bolaños-Sanchez et al. (2007) focused their study on two isolated cases characterized by very strong winds and high waves during November 2001 and March-April 2002, using MASS and ARPEGE atmospheric models and WAM and SWAN wave models. More recently Ponce de Leon and Guedes Soares (2008) compared the wave model hindcasts in the western Mediterranean Sea based on the HIPOCAS (Ratsimandresy et al., 2008) and ERA-40 reanalysis wind fields for two winter storms in November 2001. Bertotti et al. (2012) have studied the performance of seven different wind-wave systems during the Klaus storm that hit Spain and entered the western Mediterranean on January 2009.

The present study is devoted to the investigation of the performance of the recently installed WAM wave model in the eastern part of the Mediterranean Sea during the first year of the operational use at the National Observatory of Athens (NOA). The wind field is provided by the weather forecasting model BOLAM that has run operationally at NOA since 2000 (Lagouvardos et al., 2003). For the wave model verification, both buoy and satellite data have been used. The paper is arranged as follows. In Sect. 2 a detailed description of the meteorological and wave models is given, while the dataset description is given in Sect. 3. Section 4 is devoted to the results of the comparison between model and measurements, and Sect. 5 presents an example of a case study. Finally, the concluding remarks are discussed in Sect. 6.

\section{The meteorological and wave models}

The quality of wave forecasts is directly connected to the reliability of the wind forecasts computed by a meteorological model. The BOLAM model (Bologna Limited Area Model), which is used for operational weather forecasting at NOA, has been used in this study (Lagouvardos et al., 2003). The version of BOLAM is based on previous versions of the model described in details by Buzzi et al. (1998) and Buzzi and Foschini (2000). The choice of this model is based on the very encouraging results obtained for the wind field over the Ionian and the Aegean Sea. More specifically, the comparison between the wind forecasts and the measurements, provided by four buoys (supervised by NCMR) for the period September 2000-March 2001, showed that the magnitude of the wind speed mean error ranges from -1.1 to $1.4 \mathrm{~m} \mathrm{~s}^{-1}$ (Lagouvardos et al., 2003). Two nested grids have been defined for the operational chain: a coarse one covering Europe, the whole Mediterranean Sea and the northern African coasts with a 0.15 deg grid, while the inner one covers the Greek peninsula and its surrounding seas, with a grid with $0.06 \mathrm{deg}$ resolution. Thirty-six levels have been considered in the vertical, up to $10 \mathrm{hPa}$ with higher resolution close to the surface. The initial and boundary conditions of the model are given by the Global Forecasting System (GFS) model provided by the National Center for Environmental Predictions (NCEP). These consist of wind field analysis and forecasts at 6-h interval, provided on a regular long/lat grid with 0.5 deg. spatial resolution.

To provide the wave forecast, the WAM model has been used. The model is widely described in the literature (e.g. WAMDI Group, 1998; Komen et al., 1994; Bidlot et al., 2002; Janssen, 2007) for both fundamentals and applications. The model is a third generation model, based on pure physics without any assumption on the spectral shape. It considers all the main processes that control the evolution of a wave field in deep water, namely the generation by wind, the nonlinear wave-wave interactions, and the white-capping.

The WAM model has run operationally at NOA since the summer 2010. As for the meteorological models also for the wave model, two different domains have been defined: a coarse one that covers the whole Mediterranean Sea with $1 / 4$ degree grid resolution and an inner one that covers the Ionian and Aegean Sea with a 1/16 degrees grid resolution (see Fig. 1a). Note that taking the western border of the coarse grid at $6^{\circ} \mathrm{W}$ corresponds to considering the Gibraltar Strait to be closed. Although this may affect the wave conditions estimated in the nearby area, this does not influence the wave fields in the region of interest, where the inner grid is located (see its position in Fig. 1a and b). The inner grid spans from $19^{\circ}$ to $29^{\circ} \mathrm{E}$ and from $34^{\circ}$ to $41^{\circ} \mathrm{N}$. The depth of this area varies from very deep water, across the large fault lines sited in the Ionian Sea, North Aegean and in the open sea south of Crete, to relative shallow waters near the coasts of 

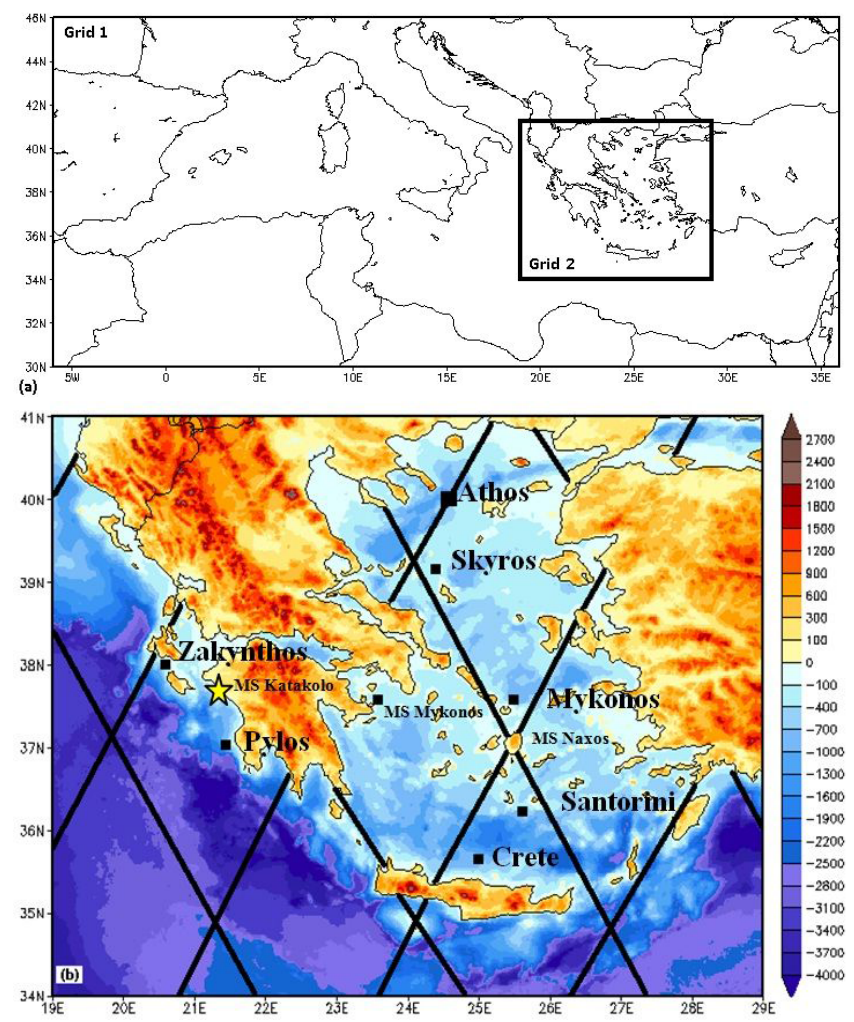

Fig. 1. (a) Extension of the WAM grids. The inner rectangle denotes the position of the finer grid. (b) Bathymetry and orography of the fine grid. The black lines denote the ground tracks of Jason-2 above Greece while the wave buoys used for validation are marked with rectangles.

continental Greece and the islands. The maximum depth of the study area is located in the south Ionian Sea $(\approx 4500 \mathrm{~m})$.

The forecast wind provided by the BOLAM model is ingested in the WAM model on the two different grids at 3-h intervals. The model provides forecast fields for $72 \mathrm{~h}$ at 3-h intervals, at the synoptic times (00:00, 03:00, 06:00... UTC).

\section{Dataset descriptions}

Two different sources of data have been used for the wave model verification. The fist source of data consists of in-situ observations from the buoys network, operated by the Hellenic Centre for Marine Research (HCMR). The locations of the eight buoys are depicted with the black rectangles in Fig. 1 and presented in Table 1. These buoys are continuously in operation; the records for the comparison with the model data are taken at 3-h intervals at synoptic times (00:00, 03:00, 06:00 ... UTC). For the verification purposes the model data in the closest sea grid point to each buoy location have been used. It should be noted that the verification is restricted to the first day of the forecast. Table 1 summarizes also the mean and the maximum significant wave height observed during the 1-yr period of the study, starting from 1 September 2010 up to 31 August 2011.

The second is space-borne altimeter-derived wave heights from OSTM/Jason-2 (CNES-NASA). Jason-2 is a low-orbit satellite, equipped with high-precision ocean altimetry that measures the distance between the satellite and the ocean surface, within a few centimeters. Jason-2 is the resumption of the two past missions: TOPEX/Poseidon and Jason1 (OSTM/Jason-2, Products Handbook, 2009). Jason-2 data are available along the satellite ground track and correspond to an average over $6-7 \mathrm{~km}$ along these tracks, with repeat cycles of about 10 days. Figure $1 \mathrm{~b}$ depicts the position of ground tracks of Jason-2 above the region of Greece. One problem consists in the availability of the data. The altimeters cannot measure close to the coasts because of the interference with the land. This depends on the dimension of the footprint of the remote signal which is of few kilometers. This means that when the satellite is flying offshore, the altimeter requires some time to work properly again. This negative effect is more frequent in the Aegean Sea because of the large number of islands. In general, Jason-2 data are not available at the same time with the model data. For the verification purposes the model output from the first day of simulation at lead times from $t+03$ up to $t+24 \mathrm{~h}$ with the closest valid time to the time of the satellite passage is used. Then the model sea grid point closest to each satellite measurement is selected for the verification.

\section{Results}

Here we discuss the results of the comparison between the significant wave height predicted by the WAM model and the data from the buoys and the altimeter, respectively. The comparison is performed over a 1-yr period from 1 September 2010 to 31 August 2011, which corresponds to the first 12 months of operational use of WAM model at NOA.

\subsection{Comparison with buoy data}

Figure 2a-h present the scatter plots of measured significant wave heights versus WAM model results for the eight buoy locations and over the 1-yr period. A characteristic of the eight comparisons is that the model tends to overestimate the wave height almost everywhere, with the exception of the two buoys located in the Ionian Sea (Zakynthos and Pylos) and in the Saronikos Bay (Aegina). From Table 2, where the general results are summarized, it is clear that the locations with the best model results are those at Athos with a best fit slope (SLO) equal to 1.07 and a correlation coefficient (CORR) equal to 0.89 (see Fig. 2a). Similar situation is found at Crete with SLO equal to 1.03 and CORR equal to 0.79 (see Fig. 2f).These buoys are both deployed in the open sea at a distance from the shore greater than $30 \mathrm{~km}$. The lowest values for scatter index SI are found at Santorini, in the southern 
Table 1. Characteristics of the buoys used in this study. The mean significant wave height and the maximum wave height are referred to the 1-yr period from 1 September 2010 up to 31 August 2011.

\begin{tabular}{llrrr}
\hline $\begin{array}{l}\text { Name } \\
\text { of Buoy }\end{array}$ & Location & $\begin{array}{r}\text { Depth } \\
(\mathrm{m})\end{array}$ & $\begin{array}{r}\text { Mean Significant } \\
\text { Wave Height }(\mathrm{m})\end{array}$ & $\begin{array}{r}\text { Maximum Significant } \\
\text { Wave Height }(\mathrm{m})\end{array}$ \\
\hline Athos & $39.97^{\circ} \mathrm{N}-24.72^{\circ} \mathrm{E}$ & 220 & 0.8 & 5.0 \\
Skyros & $39.11^{\circ} \mathrm{N}-24.46^{\circ} \mathrm{E}$ & 120 & 0.9 & 5.4 \\
Mykonos & $37.52^{\circ} \mathrm{N}-25.46^{\circ} \mathrm{E}$ & 110 & 1.0 & 4.9 \\
Aegina & $37.60^{\circ} \mathrm{N}-23.56^{\circ} \mathrm{E}$ & 210 & 0.5 & 2.0 \\
Santorini & $36.26^{\circ} \mathrm{N}-25.50^{\circ} \mathrm{E}$ & 280 & 0.9 & 3.5 \\
Crete & $35.77^{\circ} \mathrm{N}-24.93^{\circ} \mathrm{E}$ & 1303 & 0.8 & 3.7 \\
Zakynthos & $37.96^{\circ} \mathrm{N}-20.60^{\circ} \mathrm{E}$ & 254 & 0.6 & 2.8 \\
Pylos & $36.83^{\circ} \mathrm{N}-21.60^{\circ} \mathrm{E}$ & 1651 & 0.8 & 5.7 \\
\hline
\end{tabular}

Table 2. Statistics for significant wave height from the comparison at eight buoy locations.

\begin{tabular}{lrrrr}
\hline $\begin{array}{l}\text { Location } \\
\text { of buoy }\end{array}$ & $\begin{array}{r}\text { Best } \\
\text { slope }\end{array}$ & Correlation & $\begin{array}{r}\text { Scatter } \\
\text { index }\end{array}$ & $\begin{array}{r}\text { Bias } \\
(\mathrm{m})\end{array}$ \\
\hline Athos & 1.07 & 0.89 & 0.33 & 0.11 \\
Skyros & 1.11 & 0.90 & 0.32 & 0.12 \\
Mykonos & 1.09 & 0.84 & 0.34 & 0.12 \\
Aegina & 0.96 & 0.67 & 0.37 & -0.01 \\
Santorini & 1.18 & 0.74 & 0.42 & 0.17 \\
Crete & 1.03 & 0.79 & 0.30 & 0.08 \\
Zakynthos & 0.92 & 0.73 & 0.32 & -0.03 \\
Pylos & 0.89 & 0.72 & 0.36 & -0.05 \\
Mean Values & 1.03 & 0.78 & 0.34 & 0.06 \\
\hline
\end{tabular}

Aegean Sea, and Aegina, in the southern part of Saronikos Bay (values are 0.42 and 0.37 , respectively).

The overestimate of the wave height by the WAM model substantially increases for wave heights higher than $2 \mathrm{~m}$. This effect is mainly due to three isolated cases when the meteorological model produced too high wind speed and hence, as a consequence, the wave model produced too high waves. Indeed, during the period 8-9 March 2011, a northern wind speed gust exceeding $25 \mathrm{~m} \mathrm{~s}^{-1}$ was observed at the two meteorological stations Mykonos and Naxos. Similarly, high wind speeds from north were observed on 11 December 2010 at the same weather stations. As a consequence the WAM model produced high wave heights, while the observations provided by the majority of the buoys were noticeably smaller. These cases are included within the ellipses in Fig. $2 c$ and e. It is worth to mention that, when omitting these cases from the general analysis, the statistical values show an improvement. The wrong results obtained by both the meteorological and the wave models could be explained by the presence of a large number of islands in the central Aegean Sea. These islands may strongly influence the wind fields especially when it is blowing from the north. Due to the stronger wind, the wave model, as a consequence, overpredicts the wave height.
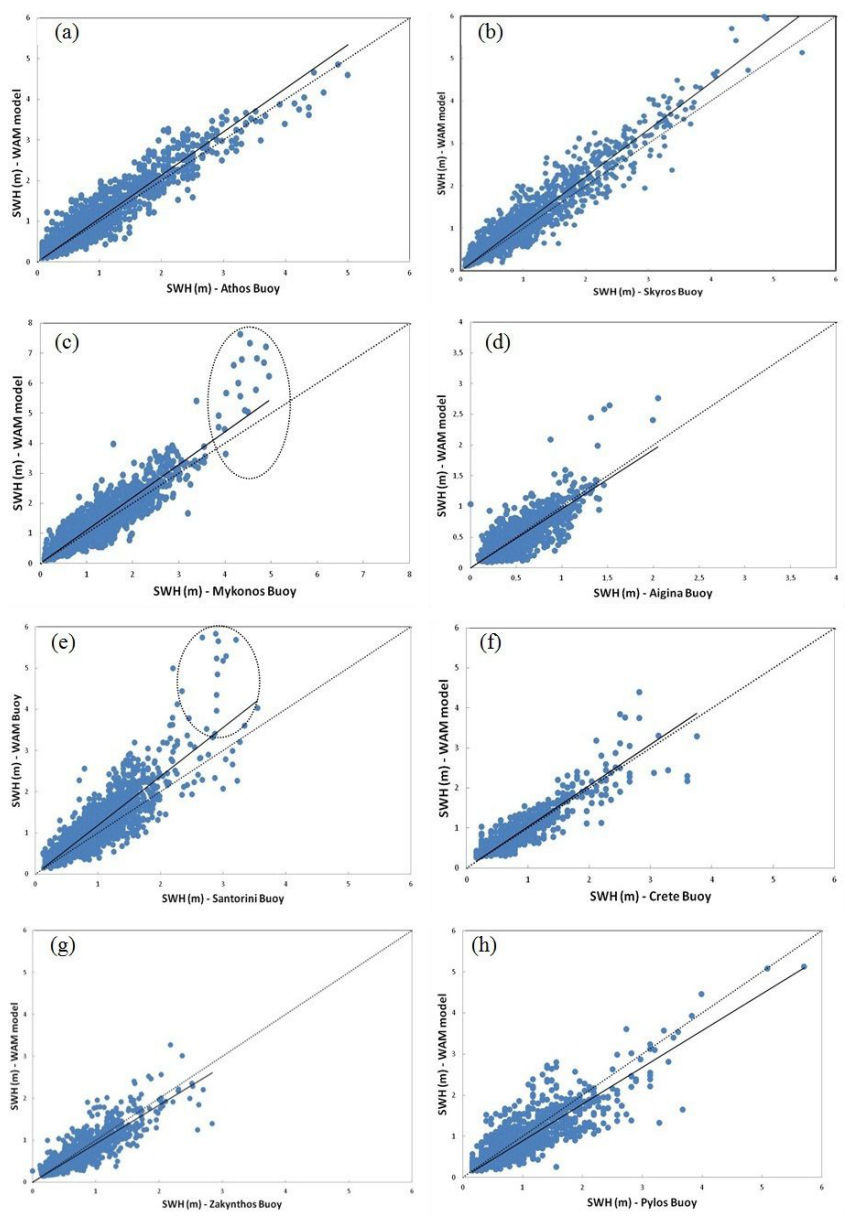

Fig. 2. Scatter plots of significant wave height, measurements versus WAM model at (a) Athos, (b) Skyros, (c) Mykonos, (d) Aegina, (e) Santorini, (f) Crete, (g) Zakynthos and (h) Pylos. The ellipses in (c) and (e) denote the two isolated cases of 8-9 March 2011 and 11 December 2010. 


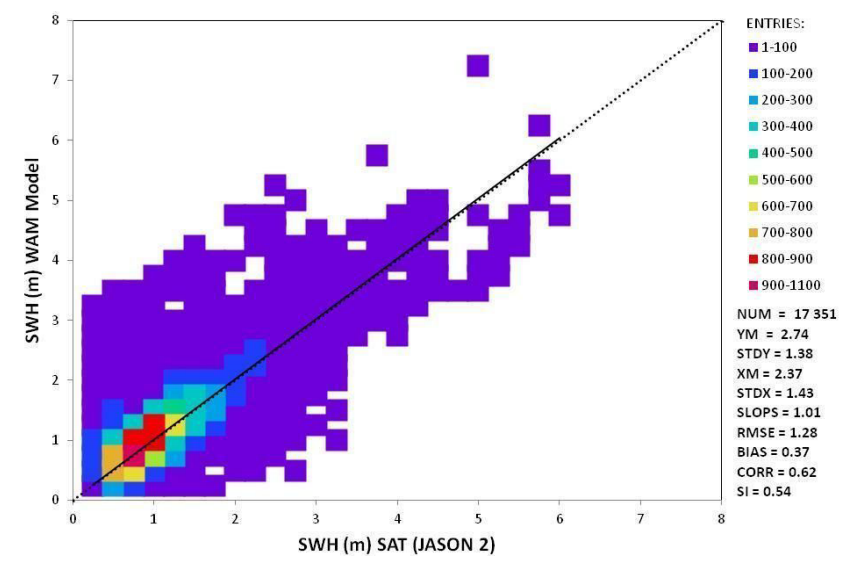

Fig. 3. Scatter diagram of the model significant wave heights vs. the corresponding Jason-2 altimeter data during the period 1 September 2010 up to 31 August 2011. The different colours (right scale) represent the numerosity in each box.

The above results are satisfactory because they are in agreement with similar studies carried out in the Mediterranean Sea. Ardhuin et al. (2007) compared the measurements from an extended network of buoys, in the western part of the Mediterranean, for a two-month period with the model results from WAM at a resolution of $0.1 \mathrm{deg}$ and found a mean best-fit slope equal to 0.95 and a mean scatter index equal to 0.35 . These values are very close to the values found in the present study and shown in Table 2. In another study, Bertotti et al. (2011) compared the data measured at the ISMAR oceanographic tower, located in the northern part of the Adriatic Sea, with the results of the WAM model for a 5 -yr period and found statistical results very close to those presented in the present study.

\subsection{Comparison with altimeter data}

Here we describe the results obtained comparing the satellite altimeters data and the corresponding WAM data for the considered 1-yr period. As it was explained in Sect. 2, the altimeters cannot measure close to the coasts and the wave data are not reliable. For that reason, when the difference between the satellite measurements and the model results exceeds twice the standard deviation, we have rejected the data. The scatter diagram displayed in Fig. 3 shows that there is a slight tendency by the model to overestimate the wave heights. The mean observed wave height is $2.37 \mathrm{~m}$ while the mean forecasted wave height is $2.74 \mathrm{~m}$. The bias is 0.37 and is substantially greater than the value obtained using the buoys (see Table 2). This can be explained by the poor accuracy of altimeter measurements near the coasts. Bertotti et al. (2011), who compared the altimeter data from ENVISAT with the results of WAM model for a 5-yr period over the Adriatic Sea, found slightly different results. More precisely, they found that there was a tendency by the model to underestimate the

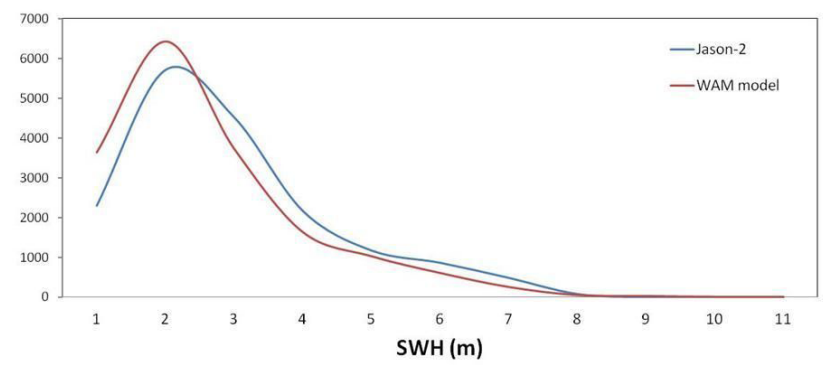

Fig. 4. Distribution of the satellite measurements and the model data in various bins. The bins follow the pattern $0-0.5,0.5-1.0,1.0-1.5$, etc.

lower wave heights, in fact that it was attributed to the local pattern of the wind field, associated for example with sea breezes. Nevertheless, the best-fit slope was equal to 1.00 , as in our analysis.

The distribution of the satellite measurements and the model data in various bins $(0-0.5,0.5-1.0$, etc.) is presented in Fig. 4. It is evident that the model has the tendency to overestimate the height for waves lower than $2.5 \mathrm{~m}$ and to underestimate it otherwise.

\section{Case study}

In order to have a better knowledge of both the meteo and wave models performance over the study area, we have chosen a peculiar case study characterized by strong winds and waves. The selected case, presented in this section, occurred on 19 February 2011, and it was characterized by strong gale winds with a maximum of observed gusts that exceeded $35 \mathrm{~m} \mathrm{~s}^{-1}$ at the automated meteorological station located at Katakolo, on the western coast of Peloponnisos (see Fig. 1b). During this day, a strong low pressure system was centered over the southern Ionian Sea, with a minimum pressure of $991 \mathrm{hPa}$ in its center, while moving eastwards it caused very strong gale winds in the southern Ionian Sea and in the maritime area south of Crete. This deep low was followed by high waves which caused significant damage over an extended coastal area of the southern part of Crete.

Figure $5 \mathrm{a}-\mathrm{d}$ show the evolution of the wave fields and the wave direction in the Aegean and Ionian Sea on the 9 February 2011. It is evident that the strong winds produced remarkable wave heights in the southern part of the Ionian Sea, where the wave heights exceeded 4.5-5 m. During the same day the system moved eastwards and produced high waves in the maritime area south of Crete. Figure $6 a-d$ provide the time series of the wave height observed at the buoys of Pylos, Crete, Mykonos and Skyros (see Fig. 1b for their position). Each plot shows both the WAM model forecast and the corresponding measured data. Out of the four selected buoys, Pylos was the most influenced by the intense low as its location was in the middle of it. The results are rather consistent 

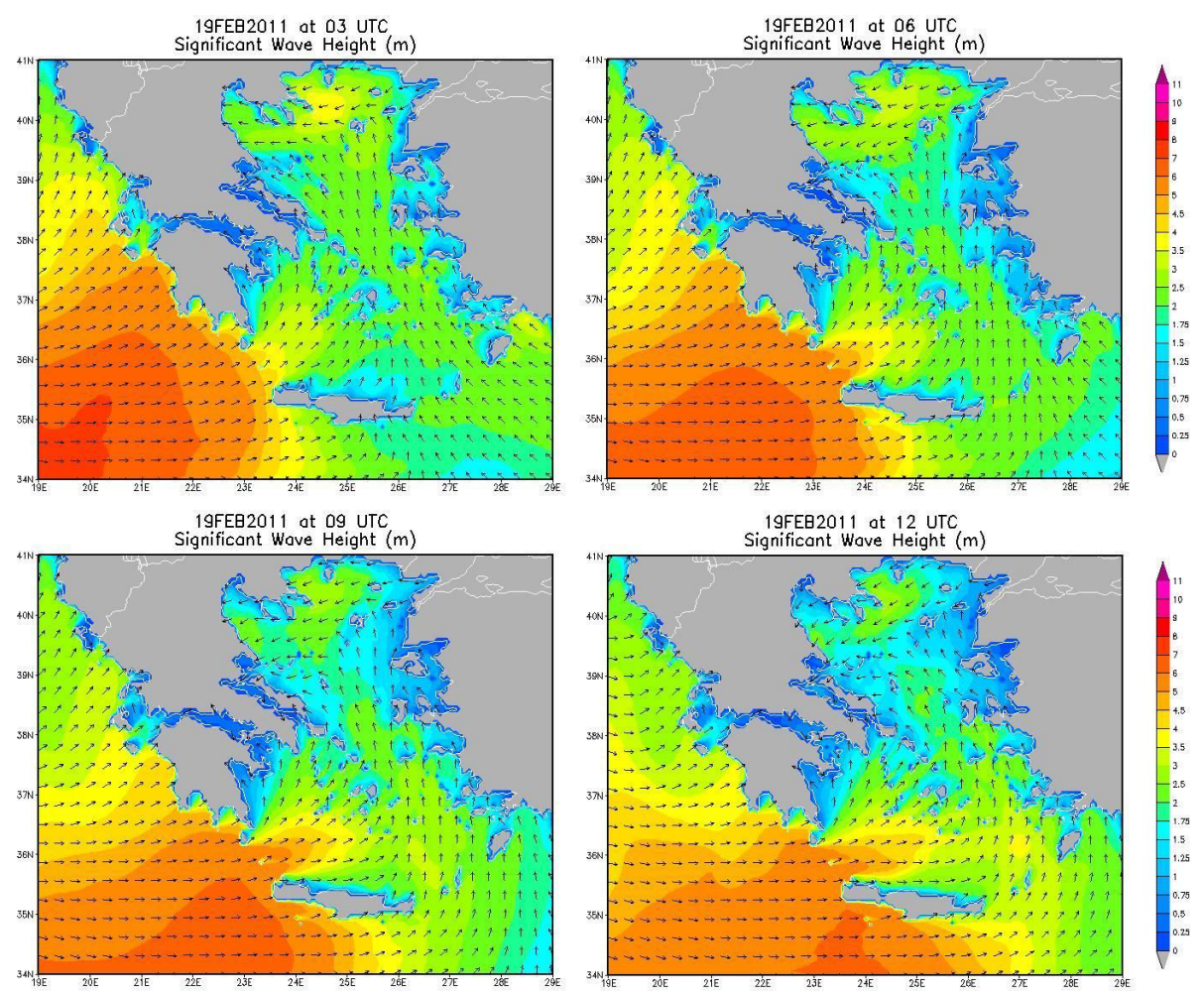

Fig. 5. Evolution of the wave height and direction produced by the first $24 \mathrm{~h}$ forecast of the WAM model. The fields refer to (a) 03:00, (b) 06:00, (c) 09:00 and (d) 12:00 UTC, 19 February. The red colours in the southern part of the region denote significant wave heights higher than $4.5 \mathrm{~m}$. The arrows represent the mean direction of the waves.
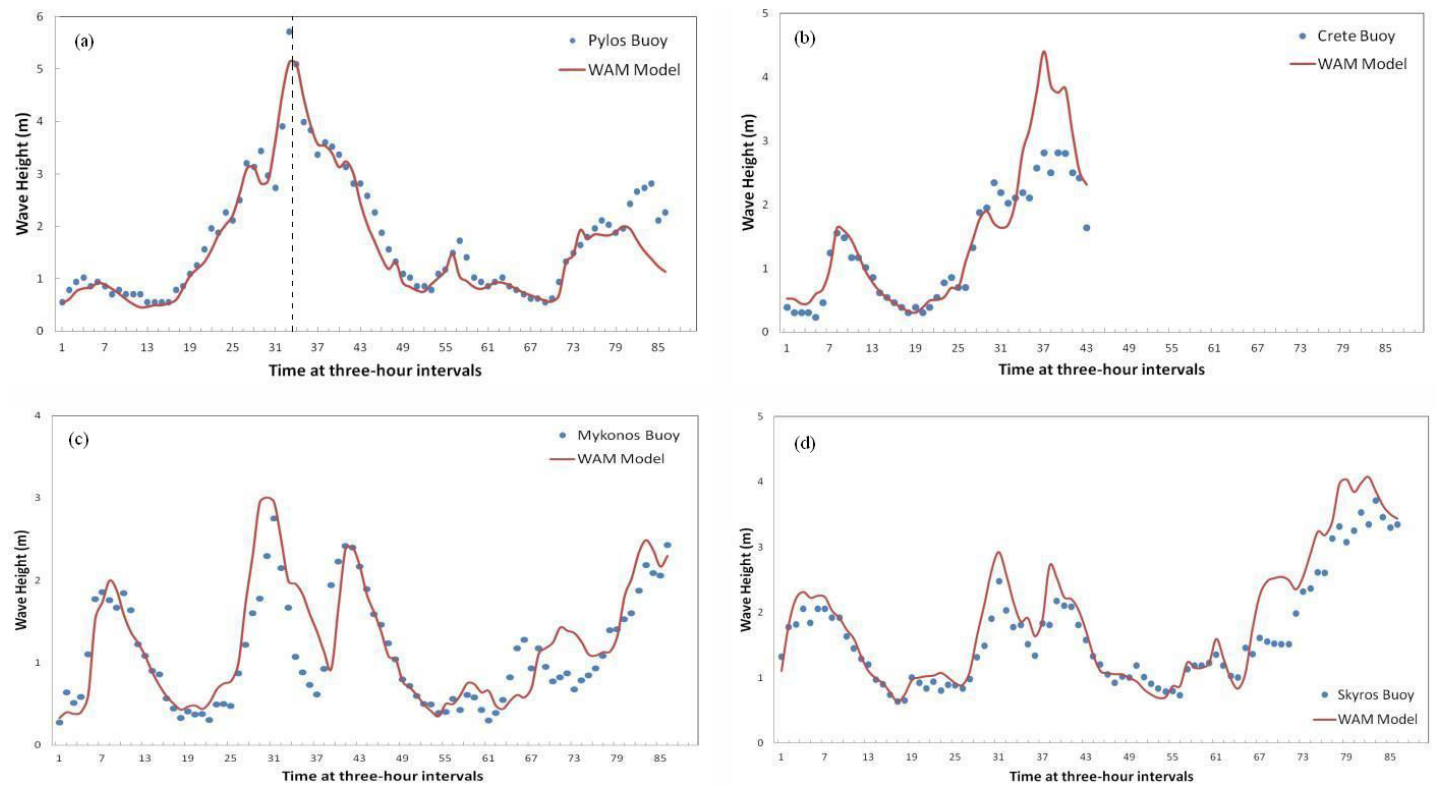

Fig. 6. (a) Time series of significant wave height at Pylos as forecast by WAM model (red line) and measured by the buoy (blue dots). Time ticks at 3-h intervals; 25 correspond to the 03:00 UTC of 18 February while 41 correspond to the 03:00 UTC of 20 February. The dotted line corresponds to the maximum observed wave height. (b) as in (a) but for Crete. Measurements were available up to 20 February. (c) as in (a) but for Mykonos and (d) as in (a) but for Skyros. 
with the measurements not only for the selected day (see the dotted line in Fig. 6a), but also for the whole analyzed period between 15 and 25 February. On the 19 February at 03:00 UTC, the observed maximum wave height reached $5.7 \mathrm{~m}$, while the forecast one was equal to $5.1 \mathrm{~m}$. This pattern seems to be maintained at the other two buoys, Mykonos and Skyros in Fig. 6c and d, respectively, even if there is a slight overestimation by the model, especially during the end of the selected period where the dominant wind direction was N-NE (not shown here). On the other hand the measurements at the Crete buoy were remarkably lower than the forecast ones. The reason is that this buoy is located in the northern area of Crete and the influence of the island plays a significant role on the definition of the wave field when the dominant winds are from the south. This example emphasizes the role of the fetch in the formulation of the wave height by the model, in regions with a large number of islands, such as the Aegean Sea, pointed out by Cavaleri and Bertotti (2004). Hence, when the wind flow is southwesterly, the WAM model succeeds in simulating the wave fields in the southern Ionian Sea, where there are no islands, while, on the contrary, in the Aegean Sea the model presents lower performance, a fact that could be attributed to the presence of the islands and especially of Crete. Crete has an extended influence both on the wind and on the wave field because of its large size and its orientation from west to east that acts as a barrier to both the southern and the northern flow (Kotroni et al., 2001).

\section{Conclusions}

This paper presents the analysis of the performance of WAM wave model over the Greek maritime areas based on one year of operational use of the model at NOA. The selected period spans from 1 September 2010 to 31 August 2011 and the area of the analysis covers the Ionian and the Aegean Sea with a resolution of 1/16 degrees. The wind fields used to drive the wave model were provided by the BOLAM model which is used for operational weather forecasting at NOA. The data used for the verification are provided by a local network of buoys in combination with altimeter satellite data. The comparisons using the two sources of measurements indicate a rather satisfactory performance of the wave model.

Although the performance of the wave models is different in the open sea and close to the coast and in general it is better in the oceans, the implementation of WAM model over the Greek seas showed, in general, encouraging results for the quality of the forecasts. The comparison between the model forecasts and the buoys measurements showed that the quality of forecast, as expected, is strongly dependent on the buoy's location. In the Ionian Sea, where the number of islands is very limited and the fetch is important, especially in case of southern wind flow, the meteo model tends to underestimate the wind speed and hence the wave energy. On the contrary, in the Aegean Sea, characterized by a large number of islands and a complex topography, especially around Crete, the model tends to overestimate the wave heights. These results have been also supported by the analysis of a case study that was characterized by high waves over the Greek seas. As for the statistical results, the mean best-fit slope for the eight selected buoys was equal to 1.03 with a scatter index equal to 0.34 and a mean bias equal to $0.06 \mathrm{~m}$. On the other hand, the comparison of the WAM model with altimeter data showed that there is a slight tendency by the model to overestimate the height of waves lower than $2.5 \mathrm{~m}$ while it underestimates the wave heights greater than $3 \mathrm{~m}$.

In any case the general conclusion that can be derived by the present study is that WAM model can provide accurate forecasts of the wave conditions over the Greek seas and therefore could be used as support for the marine activities and the marine safety purposes. Although most of the Aegean and Ionian bathymetry is deep water condition and the physics of the WAM model is capable to correctly represent the sea state, it will be very interesting in a future work to use in our simulation a coupled system WAM-SWAN in order to see the differences between the two systems, as it has been used in other studies (e.g. Rusu et al., 2008; Rusu and Soares, 2012).

Edited by: S. Tinti

Reviewed by: two anonymous referees

\section{References}

Ardhuin, F., Bertotti, L., Bidlot, J.-R., Cavaleri, L., Filipetto, V., Lefevre, J.-M., and Wittmann, P.: Comparison of wind and wave measurements and models in the Western Mediterranean Sea, Ocean Eng., 34, 526-541, 2007.

Bidlot, J.-R., Holmes, D. H., Wittmann, P. A., Lalbeharry, R., and Chen, H. S: Intercomparison of the performance of operation ocean wave forecasting systems with buoy data, Weather Forecast., 17, 287-310, 2002.

Bolaños-Sanchez, R., Sánchez-Arcilla, A., and Cateura, J.: Evaluation of two atmospheric models for wind-wave modelling in the NW Mediterranean, J. Mar. Syst., 65, 336-353, 2007.

Buzzi, A. and Foschini, L.: Mesoscale meteorological features associated with heavy precipitation in the southern Alpine region, Meteor. Atmos. Phys., 72, 131-146, 2000.

Buzzi, A., Tartaglione, N., and Malguzzi, P.: Numerical simulations of the 1994 Piedmont flood: Role of orography and moist processes, Mon. Weather Rev., 126, 2369-2383, 1998.

Bertotti, L. and Cavaleri, L.: The predictability of the "Voyager" accident, Nat. Hazards Earth Syst. Sci., 8, 533-537, doi:10.5194/nhess-8-533-2008, 2008.

Bertotti, L., Canestrelli, P., Cavaleri1, L., Pastore, F., and Zampato, L.: The Henetus wave forecast system in the Adriatic Sea, Nat. Hazards Earth Syst. Sci., 11, 2965-2979, doi:10.5194/nhess-112965-2011, 2011.

Bertotti, L., Bidlot, J.-R., Bunney, C., Cavaleri, L., Delli Passeri, L., Gomez, M., Levefre, J.-M., Paccagnella, T., Torrisi, L., Valentini, 
A., and Vocino, A.: Performance of different forecast systems in an exceptional storm in the Western Mediterranean Sea, Q. J. Roy. Meteorol. Soc., 138, 34-55, doi:10.1002/qj.892, 2012.

Cavaleri, L. and Bertotti, L.: The characteristics of wind and wave fields modelled with different resolutions, Q. J. Roy. Meteorol. Soc., 129, 1647-1662, 2003.

Cavaleri, L. and Bertotti, L: Accuracy of the modelled wind and wave fields in enclosed seas, Tellus, 56A, 167-175, 2004.

Janssen, P. A. E. M: Progress in ocean wave forecasting, J. Comp. Sci., 227, 3572-3594, 2007.

Komen, G. J., Cavaleri, L., Donelan, M., Hasselmann, K., Hasselmann, S., and Janssen, P. A. M: Dynamics and Modelling of Ocean Waves, Cambridge University Press, 1994.

Korres, G., Papadopoulos, A., Katsafados, P., Ballas, D., Perivoliotis, L., and Nittis, K.: A 2-year intercomparison of the WAMCYCLE4 and the WAVEWATCH-III wave models implemented within the Mediterranean Sea, Mediterranean Mar. Sci., 12, 129 152,2011

Kotroni, V., Lagouvardos, K., and Lalas, D.: The effect of Crete island on the Etesian winds over the Aegean Sea, Q. J. Roy. Meteorol. Soc., 127, 1917-1938, 2001.

Lagouvardos, K., Kotroni, V., Koussis, A., Feidas, C., Buzzi, A., and Malguzzi, P.: The meteorological model BOLAM at the National Observatory of Athens: Assessment of two-year operational use, J. Appl. Meteor., 42, 1667-1678, 2003.
OSTM/Jason 2: Products HandbookSALP-MU-M-OP-15815-CN, Ed 1.4, August 2009.

Ponce de León, S. and Guedes Soares, C.: On the sheltering effect of islands in ocean wave models, J. Geophys. Res., 110, C09020, doi:10.1029/2004JC002682, 2005.

Ponce de León, S. and Guedes Soares, C.: Sensitivity of wave model predictions to wind fields in the western Mediterranean Sea, Coast. Eng., 55, 920-929, 2008.

Ponce de Leon, S. and Guedes Soares, C: The sheltering effect of the Balearic Islands in the hindcast wave field, Ocean Eng., 37, 603-610, 2010.

Ratsimandresy, A. W., Sotillo, M. G., Carretero Albiach, J., Alvarez Fanjul, E., and Hajji, H.: A 44-year high-resolution ocean and atmospheric hindcast for the Mediterranean Basin developed within the HIPOCAS Project, Coast. Eng., 55, 827-842, 2008.

Rusu, L. and Guedes Soares, C.: Wave Energy Assessments in the Azores Islands, Renewable Energy, 45, 183-196, 2012.

Rusu, L., Pilar, P., and Guedes Soares, C.: Evaluation of the Wave Conditions in Madeira Archipelago with Spectral Models, Ocean Eng., 35, 1357-1371, 2008.

WAMDI group: The WAM model - a third generation ocean wave prediction model, J. Phys. Ocean., 18, 1775-1810, 1988. 